\title{
Effect of Medium Components on Biodegradation of Phenol by an Indigenous Culture of Pseudomonas Citronellolis N1 Isolated from Coke Oven Wastewater
}

\author{
Namita Panigrahi, Manas Barik, Naresh Kumar Sahoo
}

\begin{abstract}
Phenolic compounds are listed under priority pollutants by US EPA, and their concentration in effluent of coke oven industries reached to $1000 \mathrm{mg} l^{-1}$. However, investigation on biodegradation of phenolics from coke oven wastewater is found to be scanty. Therefore, an indigenous pseudomonas species with high toxicity tolerance and phenolic degradation abilities has been isolated from coke oven wastewater. In order to enhance the efficiency of phenol and to the study the interaction effect exists among them the significant media components are optimized employing response surface methodology (RSM) and central composite design (CCD RSM. Result reveals that MgSO4 plays considerable influence on biodegradation of phenol degradation by the indigenous pseudomonas species. Further, among the three independent variables, interaction effect between $\mathrm{MgSO}_{4}$ and $\mathrm{FeCl}_{3}$ found to be significant on degradation of phenol. The optimum values of the media constituents are as follows: 0.094 $\mathrm{mgl}^{-1}$ of $\mathrm{NaCl}, 0.019 \mathrm{mgl}^{-1} \mathrm{FeCl} 3$ and $0.1681 \mathrm{mgl}^{-1}$ of $\mathrm{MgSO}_{4}$ Almost completely biodegradation of phenol is achieved at 900 $\mathrm{mgl}^{-1}$ of phenol within a short time period of $24 \mathrm{~h}$. Further, at this optimized culture condition almost completely degradation of phenol was achieved even at a very high initial concentration of $1500 \mathrm{mgl}^{-1}$ within a shorter time period of $95 \mathrm{~h}$. Thus, indigenous Pseudomonas species found to be a potential candidate for degradation of high concentration of phenol from of coke oven wastewater.
\end{abstract}

Keywords: Phenol, Pseudomonas citronellolis N1, Biodegradation, medium components, central composite design

\section{INTRODUCTION}

The major industries that releases phenolic contaminated wastewater such as iron and steel manufacturing coke ovens plant, phenolic resin manufacturing, petroleum refineries and petrochemicals, paper pulp, herbicide manufacturing [1$3]$. Iron and steel plants industry produces enormous coke oven wastewater during the conversion process of coal to coke. The coke oven wastewater comprises predominantly phenolic compounds in the ranges of 50-1200 mgl ${ }^{-1}$ [4]. These phenolic pollutants are very often leaches through soil and consequently polluted the groundwater [5]. The World Health Organization (WHO) prescribed $1 \mathrm{mgl}^{-1}$ of phenol in drinking water as the maximum permissible limit [6]. The phenolic compounds are well known teratogenic as well as

Revised Manuscript Received on September 14, 2019.

Namita Panigrahi, Department of Chemistry, Environmental Science and Technology programme, ITER, Siksha'O'Anusandhan (Deemed to be University), Bhubaneswar, Odisha, India- 751030

Manas Barik, Department of Chemistry, Environmental Science and Technology programme, ITER, Siksha'O'Anusandhan (Deemed to be University), Bhubaneswar, Odisha, India- 751030

Naresh Kumar Sahoo, Department of Chemistry, Environmental Science and Technology programme, ITER, Siksha'O'Anusandhan (Deemed to be University), Bhubaneswar, Odisha, India- 751030 carcinogenic in nature. Therefore, phenolic compounds are listed aspriority pollutant by the U.S. environmental protection agency. Various physicochemical methods like, adsorption, electrolytic oxidation, photocatalysis, ozonization etc. have been studied for the removal of phenol from contaminated wastewater [4]. However, due to high cost, incompletely degradation and generation of toxic byproducts are some of the major limitation of the above mentioned process.

The eco-friendly biological process is the ultimate process for removal of these toxic phenolic compounds due its several advantages. However, treatment of phenolic wastewater faces many challenges due to its inhibitory effects on the viable cells of the microorganism. Therefore, to eliminate higher concentration of phenol from industrial effluents, it is peculiarly significant to isolate appropriate microorganism that can tolerate and efficiently degrade phenol from contaminated wastewater even at a high concentration. However, investigation on treatment of coke oven wastewater using microbial treatment is very scanty, except few studies in china and South Korea. Further, most of these treatment processes does not meet the discharge limits and occurrence of process instability and inhibition leading to inconsistent or poor performance are the major concern of these techniques [7-8]. Therefore, it is crucial very crucial to isolate potential microorganism with high toxic high tolerance capacity and degrade toxic phenolic pollutants even at a very high concentration in presence of wide different type of other pollutants present in real coke oven wastewater..

Culture media components play a vital role to regulate the enzymatic process of microorganism consequently affects efficiency of pollutant degradation. Thus, application of unoptimized and conventional media components seems to be dubious for growth of the culture and its ability of pollutants degradation. For instance, sulphate and nitrate are very essential nutrients for growth of $A$. chlorophenolicus A6, however, when the concentrations of these compounds exceed beyond certain limits it inhibits the biodegradation process [9-10]. Similarly, addition of chlorinated compounds such as $\mathrm{NaCl}$ and $\mathrm{FeCl}_{3}$ and $\mathrm{CaCl}_{2}$ in culture medium increases the concentration of chloride ion which exhorts toxicity effect on microbial cell consequently 
oxidizes and inhibits the metabolism of the microorganism. Therefore, it is very important to study individual roles plays by these media components and their interaction on each other on biodegradation of phenol by the newly isolated Pseudomonas species. Statistical design of experiments such as; response surface methodology and central composite design has been employed to optimize the media constituents of the newly isolated Pseudomonas species to increase the efficiency of phenol degradation. The traditional "one-variable-at-a-time approach" ignores the interactions effect exist among the different media constituents [11]. In contrast, statistically based experimental designs like response surface methodology (RSM) and central composite design has been effectively applied to study the effects of several factors on the response as well as main and interaction effects exist among the substrates [12-13].

Thus, the specific objectives of the present investigation are; (i) evaluate the performance of newly isolated Pseudomonas citronellolis N1 in biodegradation of phenol as the sole source of carbon and energy (ii) elucidate the individual roles played by these media components and their interaction on each other biodegradation of phenol by the isolated Pseudomonas species (i.e. synergistic, antagonistic) iii) Optimization of various medium components by employing central CCD and RSM.

\section{MATERIALS AND METHODS}

\section{A. Chemicals and Reagents}

In the present study experimental work were carried out using laboratory grade and analytical grade chemicals procured from Hi-Media, Merck India and Sigma Aldrich.

\section{B. Preparation of Inoculums}

The optimization of media components was executed by utilizing a minimum salts medium (MSM) $\left(\mathrm{g} \mathrm{l}^{-1}: \mathrm{K}_{2} \mathrm{HPO}_{4}\right.$ 2.6, $\mathrm{NaNO}_{3}$ 0.58, $\mathrm{KH}_{2} \mathrm{PO}_{4} 0.4, \mathrm{MgSO}_{4} 0.17, \mathrm{FeCl}_{3} 0.002$ and $\mathrm{CaCl}_{2}$ 0.038) with $900 \mathrm{mgl}^{-1}$ of phenol [9]. The $\mathrm{pH}$, temperature and agitation speed of the culture medium was maintained at $7.4,32{ }^{\circ} \mathrm{C}$ agitation speed $210 \mathrm{rpm}$ respectively. The seed culture cells were grown overnight in the above mentioned MSM and culture conditions in an incubator shaker with $900 \mathrm{mgl}^{-1}$ of phenol as the only carbon source and energy. The overnight grown cells were centrifuged $\left(8000 \mathrm{~g}, 20 \mathrm{~min}\right.$ at $\left.10^{\circ} \mathrm{C}\right)$, washed in $1 \mathrm{X}$ phosphate buffer saline (PBS, pH 7.5) and used as the inoculums for the optimization process. The initial biomass concentration in the inoculums was $0.1 \mathrm{OD}_{600 \mathrm{~nm}}$. Details about the experimental run and combination of media components in the biodegradation flasks are shown in Table 1. Following inoculations the flasks were incubated in orbital shaking incubator at $32^{\circ} \mathrm{C}$ and $210 \mathrm{rpm}$. The collected samples were filtered using $0.45 \mu \mathrm{m}$ milipore filter paper and the filtrates were used for estiamation percentage of toxicity removal by resazurin assay and remaining phenol 4-aminoantipyrine methods [14]. Samples were collected at regular intervals of time for analysis of residual concentration of phenol. The obtained results were analyzed by employing a statistical software package MINITAB, Release15.1, PA, USA.
C. Optimization of culture conditions using central composite design (CCD)

In an attempt to increase the efficiency of phenol biodegradation Pseudomonas citronellolis N1, the highly significant screened media components such $\mathrm{NaCl}, \mathrm{FeCl}_{3}$, $\mathrm{MgSO}_{4}$ were optimized using response surface methodology and central composite design. The center point values $(0)$ indicates the general concentration of these media components reported in literature and based on it the high $(+1)$ and low (-1) values of these media constituents were estimated. The following equation was used to calculate the coded values of these media components.

$$
x_{i}=\frac{U_{i}-U_{0}}{\Delta U}
$$

Where, $X_{i}$ represents the coded level $(-1,0,+1)$ of these media components. $\Delta \mathrm{U}$ stand for the step change and $\mathrm{U}_{0}$ represents the uncoded level of these media components at centre point. $\mathrm{U}_{\mathrm{i}}$. denotes the uncoded level of these independent parameters. As per central composite design, The total numbers of combinations of these media components were calculated by applying the following formula: $2^{\mathrm{k}}+2 \mathrm{k}+\mathrm{n}_{0}$, i.e. $20=2^{3}+2 \times 3+6$, where $\mathrm{k}$ denotes for the number of independent parameters and the number of center point is denoted by $\mathrm{n}_{0}$. The levels of the different media components employed in the present study is shown in Table 1. A total 14 different combinations of the media components were carried out in addition six number of center points (replicates) were taken to find out the experimental error in the CCD. In all the twenty Erlenmeyer flasks $100 \mathrm{ml}$ of MSM, $900 \mathrm{mgl}^{-1}$ of phenol was added. The experimental data's obtained in the present study were fitted to a second order polynomial model as given below.

$$
Y=\beta_{0}+\sum_{i=1}^{k} \beta_{i} X_{i}+\sum_{i=1}^{k} \beta_{i i} X_{i}^{2}+\sum_{i} \sum_{j} \beta_{i j} X_{i} X_{j}
$$

Where, $\mathrm{y}$ represent the $\%$ of predicted phenol degradation, $k$. denotes the number of factors $X_{i}$ and $X_{j}$ are the independent variables, $\beta_{0}$ stands for the offset term, $\beta_{\mathrm{i}}$ represents $i^{\text {th }}$ linear coefficient, $\beta_{\text {ii }}$ denotes the $i^{\text {th }}$ quadratic coefficient and $\beta_{\mathrm{ij}}$ represents the $\mathrm{ij}{ }^{\text {th }}$ interaction coefficient. The results obtained in the study were statistically analyzed in the form of ANOVA as well as Student's' test by applying the MINITAB software (15.1 PA, USA). 
Table 1 The range and levels of the media components employed in the investigation

\begin{tabular}{llllll}
\hline $\begin{array}{l}\text { Independent } \\
\text { variables }\left(\mathbf{g l}^{-1}\right)\end{array}$ & $\mathbf{- \alpha}$ & $\mathbf{- 1}$ & $\mathbf{0}$ & $\mathbf{+ 1}$ & $+\boldsymbol{\alpha}$ \\
& & & & & \\
\hline $\mathrm{NaCl}$ & 0.03 & 0.06 & 0. & 0.14 & 0.1 \\
& 7 & & 1 & & 672 \\
$\mathrm{FeCl}_{3}$ & 0.00 & 0.01 & 0. & 0.02 & 0.0 \\
& 73 & 25 & 0 & 75 & 326 \\
$\mathrm{MgSO}_{4}$ & 0.07 & 0.12 & 0. & 0.27 & 0.3 \\
& 38 & 5 & 2 & 5 & 261
\end{tabular}

\section{Analytical methods}

Estimation of phenol was carried out by 4aminoantipyrine method [14]. Chemical oxygen demand of the collected samples was determined by as per [14] using a COD digester (HACH, USA). Percentage of toxicity removal was calculated using Resazurin reduction assay method [15].

\section{RESULTS}

\section{A. Optimization of Culture Conditions using RSM and $C C D$}

In order to increase the efficiency of phenol biodegradation of the newly isolated Pseudomonas citronellolis $N 1$ the levels of the significant influential culture media components such as; $\mathrm{NaCl}, \mathrm{FeCl}_{3}$ and $\mathrm{MgSO}_{4}$ were varied as per the CCD. The experimental data on phenol biodegradation were fitted to the second order polynomial model as given in equation 3 . The second-order polynomial model in coded unit elucidates the individual function of the media components and their second-order interactions on biodegradation of phenol by the microorganism.

$$
\begin{aligned}
& y=67.2+189 X_{1}-228 X_{2}+84.6 X_{3}-1561 X_{1}^{2}+17585 X_{2}{ }^{2}-532 X_{3}{ }^{2}+3208 X_{1} X_{2} \\
& +258 X_{1} X_{3}+3591 X_{2} X_{3}
\end{aligned}
$$

Where $Y_{1}$ stands for $\%$ phenol biodegradation, $X_{1}$ is $\mathrm{NaCl}, X_{2}$ denotes for $\mathrm{FeCl}_{3}$ and $X_{3}$ represents $\mathrm{MgSO}_{4}$. The positive sign of this coefficient meant that phenol degradation was favored with the respective media components.

The degree of fit of the obtained experimental data to the polynomial model is evaluated based on its coefficient of determinations $\left(\mathrm{R}^{2}\right)$. The coefficient of determination values represents degrees of variability in the observed response can be elucidated by the experimental parameters and their interactions. In general, $\mathrm{R}^{2}$ values greater than 0.75 is reported as a benchmark for most of the data variability. In the present study the regression model fitted the experimental data very well with a high determination coefficient values of 0.86 , indicates the accuracy of the empirical model in describing experimental data. Further, its statistical implication was authenticated by the $F$ statistics. The ANOVA for biodegradation of phenol by newly isolated Pseudomonas species is given in Table 2. ANOVA reveals whether the variations observed in the polynomial model is significant or insignificant in comparison with the experimental results. The $F$ statistics is determined based on the ratio of adjusted mean square of regression to the adjusted mean square of residual. The higher the values of $\mathrm{F}$ signify the experimental data is very good fitted with the regression model. In the present study the $F$-value is estimated to be high i.e. 6.3 , which clearly indicating regression model is describing majority of the variation in the response with more accurately. In generally, higher $\mathrm{F}$ value with lower $P$-value indicates a higher significant of the corresponding coefficient [16].

Table 2. ANOVA of phenol biodegradation in the

\begin{tabular}{|c|c|c|c|c|c|}
\hline Source & $\begin{array}{l}\text { D } \\
\text { F }\end{array}$ & $\begin{array}{l}\text { Adj } \\
\text { SS } \\
\end{array}$ & $\begin{array}{l}\text { Adj } \\
\text { MS }\end{array}$ & $\begin{array}{l}\text { F- } \\
\text { Value }\end{array}$ & $\begin{array}{l}\text { P- } \quad \mathbf{R}^{2} \\
\text { Valu } \\
\text { e }\end{array}$ \\
\hline Model & 9 & $\begin{array}{l}328.9 \\
9\end{array}$ & 36.55 & 6.3 & $\begin{array}{ll}0.00 & 85.5 \\
4 & 6\end{array}$ \\
\hline Linear & 3 & 81.24 & 27.08 & 4.69 & $\begin{array}{l}0.02 \\
7\end{array}$ \\
\hline Square & 3 & $\begin{array}{l}202.8 \\
9\end{array}$ & 67.63 & 11.72 & $\begin{array}{l}0.00 \\
1\end{array}$ \\
\hline $\begin{array}{l}\text { 2-Way } \\
\text { Interaction }\end{array}$ & 3 & 44.85 & 14.95 & 2.59 & $\begin{array}{l}0.11 \\
1\end{array}$ \\
\hline Error & 10 & 57.22 & 5.77 & & \\
\hline Pure Error & 5 & 0.665 & 0.111 & & \\
\hline Total & 19 & $\begin{array}{l}386.7 \\
1\end{array}$ & & & \\
\hline
\end{tabular}
optimization study.

incorrectly rejecting the null hypothesis when it is actually true; F Fisher's F value (ratio of MS owing to the model by that due to error),

As shown in Table 2, the higher the $F$ with lower $p$ values (0.027) of the main effects reveals that, a particular single medium component plays significant role on biodegradation of phenol than the two-way interaction effects $(p=0.111)$. The above findings authenticated that the second-order polynomial model is adequate in predicting the phenol biodegradation by the microorganism. In order to evaluate the significance of each term in the model, student's $t$-test was carried out and the results are presented in Table 3. Generally a model term is considered as high significance, when $P$ value is low and $t$ value is high. In the present study both the linear and interaction term are showing significant effect on biodegradation of phenol as shown in Table 4. It is found that the regression coefficients of linear terms in the model for $\mathrm{MgSO} 4$ are proved to be very high significant $(P<0.006)$. The initial concentration of $\mathrm{MgSO} 4$ plays a strong negative effect on biodegradation of phenol. This clearly reveals that, with increase in concentration of $\mathrm{MgSO} 4$ in the media components, decreases the efficiency phenolic degradation by the Pseudomonas species. Further, the interaction effect 
between $\mathrm{FeCl}_{3}$ and $\mathrm{MgSO} 4$ estimated to be positive with 94\% confident level $(P \leq 0.039)$ on biodegradation of phenol by the isolated Pseudomonas species. On the other hand, interactions effects between the other culture media components found to insignificant $(P>0.284)$ on biodegradation of phenol. This investigation revealed that, biodegradation of phenol is reduced largely due to $\mathrm{MgSO} 4$ (-3.84). Further, it indicates that phenol degradation performance is enhanced more due to interaction between $\mathrm{FeCl}_{3}$ and $\mathrm{MgSO} 4$ (5.71) than due to other media constituents. Whereas, any other interaction between these culture media components is found to be insignificant on phenol biodegradation (Table 3).

Table 3 Student's $t$-test for \% of phenol biodegradation in the present investigation

\begin{tabular}{llll}
\hline Term & Coef & T-Value & P-Value \\
\hline Constant & 80.52 & 82.18 & 0.000 \\
$\mathrm{NaCl}\left(\mathrm{X}_{1}\right)$ & -0.49 & -0.45 & 0.661 \\
$\mathrm{FeCl}_{3}\left(\mathrm{X}_{2}\right)$ & 1.36 & 1.25 & 0.241 \\
$\mathrm{MgSO}_{4}\left(\mathrm{X}_{3}\right)$ & -3.84 & -3.51 & 0.006 \\
$\mathrm{X}_{1}{ }^{2}$ & -7.06 & -3.95 & 0.003 \\
$\mathrm{X}_{2}{ }^{2}$ & -2.80 & -1.56 & 0.149 \\
$\mathrm{X}_{1}{ }^{3}$ & -8.46 & -4.72 & 0.001 \\
$\mathrm{X}_{1} * \mathrm{X}_{2}$ & 2.72 & 1.13 & 0.284 \\
$\mathrm{X}_{1} * \mathrm{X}_{3}$ & 2.19 & 0.91 & 0.383 \\
$\mathrm{X}_{2} * \mathrm{X}_{3}$ & 5.71 & $2 . .38$ & 0.039 \\
\hline
\end{tabular}

Figure 1 presented the normal probability plot on biodegradation of phenol, from the Figure 1 it is observed that the experimental data were very good fitted to the quadratic model equation at high accuracy. To study reveal the main and interaction effects between these culture parameters the experimental data are represented in the form of response surface contour plots. In general, saddle point or elliptical nature of response surface contour plots reveals presence of significant interaction effect [17].

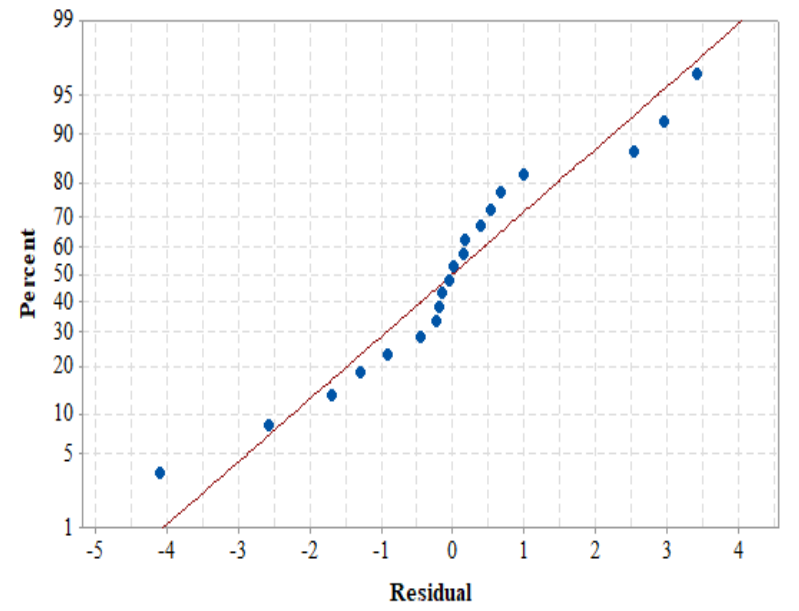

Figure 1 Normal probability plot of the experimental data on biodegradation of phenol by the Pseudomonas species.

The contour plots between $\mathrm{FeCl}_{3}$ and $\mathrm{MgSO} 4$, as well as between $\mathrm{NaCl}$ and $\mathrm{MgSO}_{4}$ are shown in Figure 2 (a) Figure 2 ( b) respectively.
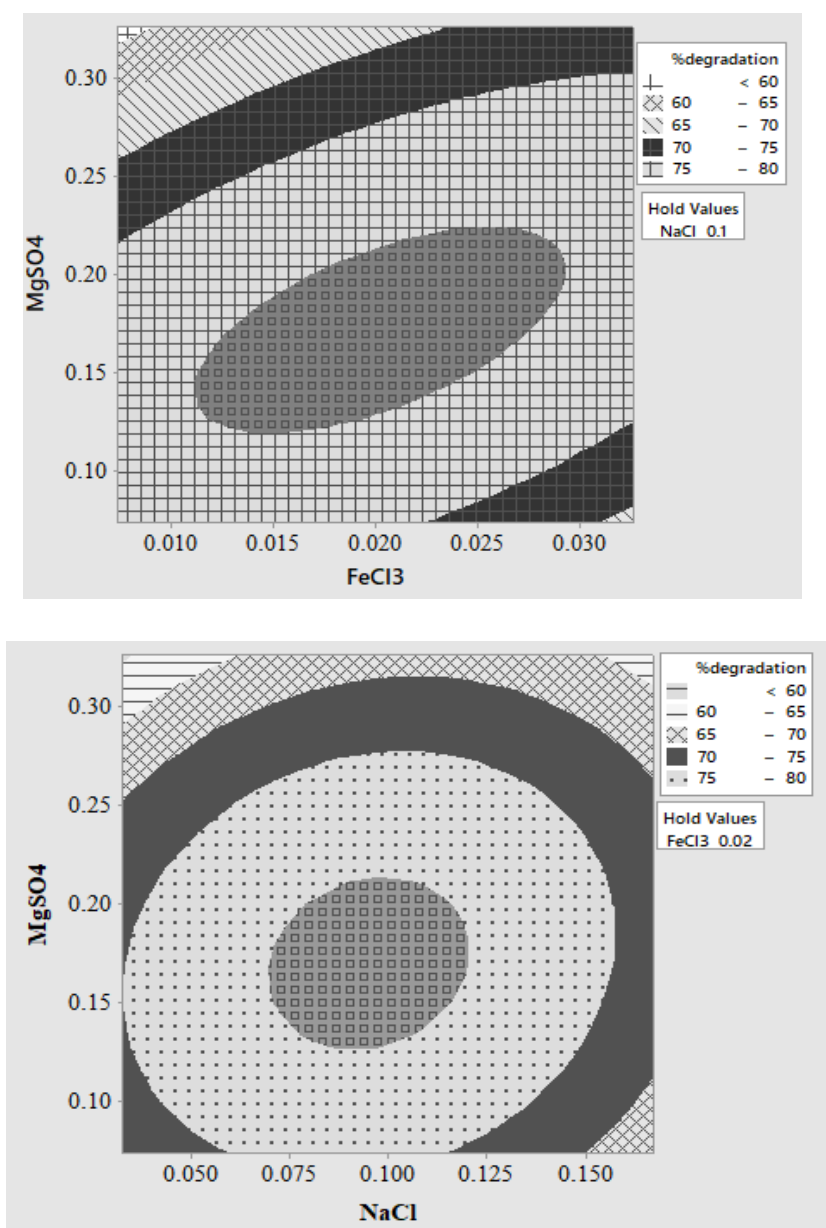

Figure 2 Two dimensional response surface contour plot demonstrate the relationship (a) $\mathrm{FeCl}_{3}$ and $\mathrm{MgSO}_{4}$

(b) $\mathrm{NaCl}$ and $\mathrm{MgSO}_{4}$ on phenol biodegradation by Pseudomonas citronellolis N1.

However, elliptical nature of the counter plot between $\mathrm{FeCl}_{3}$ and $\mathrm{MgSO}_{4}$ found to be more prominent as shown in Figure 2 (a). This clearly reveals the strong interaction between $\mathrm{FeCl}_{3}$ and $\mathrm{MgSO}_{4}$. Whereas, the contour plots between $\mathrm{NaCl}$ and $\mathrm{MgSO}_{4}$ as shown in Figure 2 (b) is a perfect circular in nature which reveals the absence of any interaction between these two parameters. The mutual effect of $\mathrm{FeCl}_{3}$ and $\mathrm{MgSO}_{4}$ on phenol biodegradation is shown in the forms of 3 dimensional response surface plot as shown in Figure 3. From the response surface plot it is observed that efficiency of phenol biodegradation steadily increases with increase in concentration of $\mathrm{FeCl}_{3}$, however, the phenol degradation increases up to a concentration of 2.8 $\mathrm{mgl}^{-1}$ and beyond this concentration the phenol degradation decreases, this fact reveals the positive interaction effect exist between the two media components. For example, keeping the concentration of $\mathrm{MgSO}_{4}$ at a constant value of $0.28-0.3 \mathrm{mgl}^{-1}$, the percentage of phenol removal is continuously increases with increase in concentration of $\mathrm{FeCl}_{3}$ and more than $94 \%$ of phenol removal has been achieved at $0.03 \mathrm{mgl}^{-1}$ of $\mathrm{FeCl}_{3}$, whereas, degradation of phenol was drop down to $80 \%$ at $0.01 \mathrm{mgl}^{-1}$ of $\mathrm{FeCl}_{3}$. This indicates the effect of $\mathrm{FeCl}_{3}$ on biodegradation of phenol by the Pseudomonas species.

Blue Eyes Intelligence Engineering

\& Sciences Publication

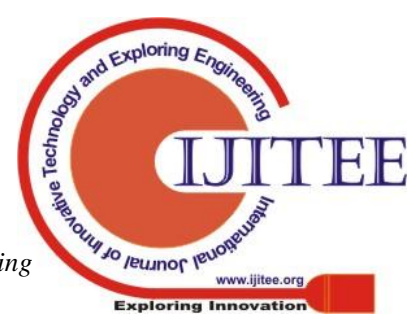




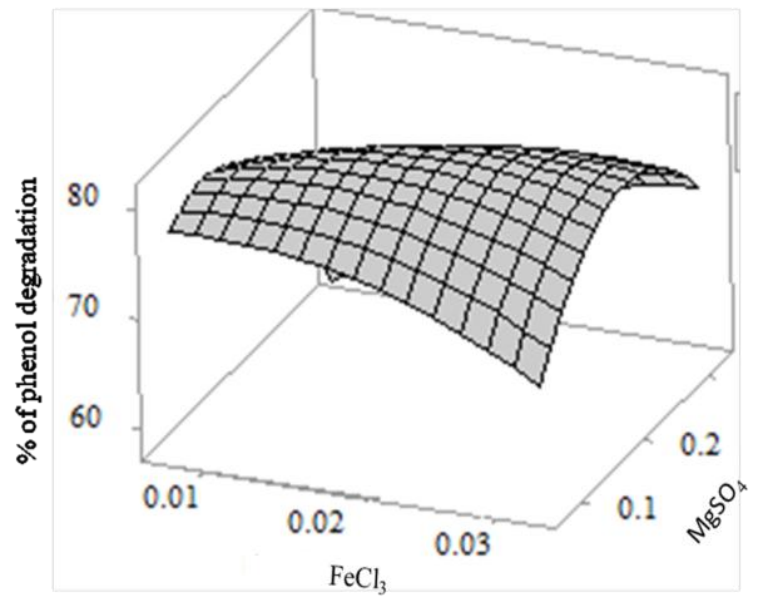

Figure 3 Three dimensional response surface plots illustrate the relationship between $\mathrm{FeCl}_{3}$ and $\mathrm{MgSO}_{4}$ on phenol biodegradation by the Pseudomonas citronellolis N1.

Thus, using the CCD $0.094 \mathrm{mgl}^{-1}$ of $\mathrm{NaCl}, 0.019 \mathrm{mgl}^{-1}$ $\mathrm{FeCl}_{3}$ and $0.1681 \mathrm{mgl}^{-1}$ of $\mathrm{MgSO}_{4}$ is found optimum for degradation of phenol by the newly isolated Pseudomonas species as demonstrated in Figure 4.

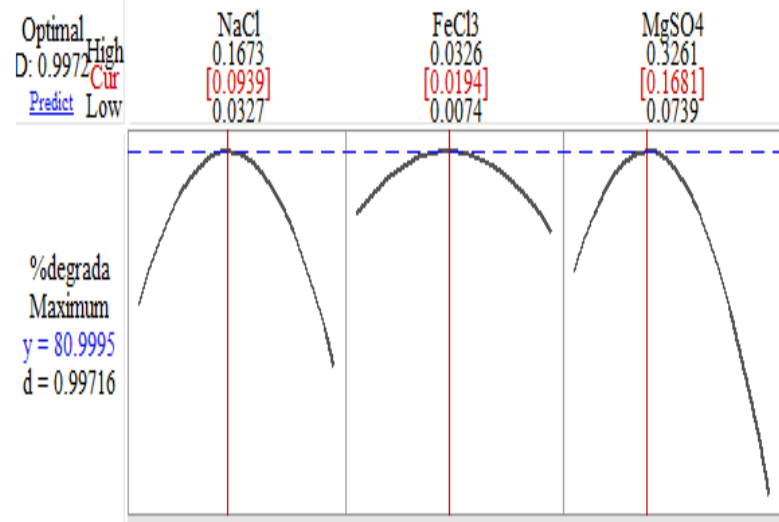

Figure 4. Optimization plot showing the optimum level of culture parameters.

\section{B. Validation of the model}

The model was validated using $100 \mathrm{ml}$ of MSM with 900 $\mathrm{mgl}^{-1}$ of phenol in a $250 \mathrm{ml}$ of Erlenmeyer flask. Under the model predicted optimized concentration of media components i.e. $\mathrm{NaCl}, \mathrm{FeCl}_{3}$ and $\mathrm{MgSO}_{4}$, the remaining concentration of the media components were kept at their respective centre point value.. Results revealed that almost completely degradation of phenol was achieved at an initial concentration of $900 \mathrm{mgl}^{-1}$ within short time period of $24 \mathrm{~h}$, which is well correlated with that of the model predicted values.

\section{DISCUSSION}

In general the inorganic salts such as $\mathrm{NaCl}, \mathrm{FeCl}_{3}$ and MgSO4 play a vital role for growth of microbial cell however, at certain high concentrations of the inorganic salts also plays a negative effect on the growth of the microbial cells. In this study, optimum levels of these inorganic salts are as follows; $0.094 \mathrm{mgl}^{-1}$ of $\mathrm{NaCl}, 0.019 \mathrm{mgl}^{-1} \mathrm{FeCl}_{3}$ and $0.1681 \mathrm{mgl}^{-1}$ of $\mathrm{MgSO}_{4}$. The lower optimum value obtained in the present study might be the presence of excess amount of chloride and sulphate ions in the culture medium which inhibits the growth of the microorganism as well as its phenol degradation activities. Similar effects of chloride ions on biodegradation of various pollutants for example, polychlorinated biphenyl (PCB) and chlorobenzenes have been reported in literature [9,18]. Similarly presence of sulphate ion concentration in culture medium plays pivotal role in biodegradation of Aroclor 1242, polychlorinated biphenyl, nona-and octa-chlorobiphenyls, [19-20]. Similarly, the optimum concentration of sodium chloride for biodegradation of phenol by the newly isolated Pseudomonas species is s slightly high in comparison with that of reported literature. However, in the present investigation further increase in concentration of $\mathrm{NaCl}$ and $\mathrm{FeCl}_{3}$ did not improve the growth of the culture and its phenol degradation capacity which might be due the accumulation of excess concentration of chloride ions $\left(\mathrm{Cl}^{-}\right)$ as a result chloride ions aggravates the microbial toxicity by oxidizing the microbial cells [21]. At the optimum medium constituents, the newly isolated Pseudomonas species found to be degraded $900 \mathrm{mgl}^{-1}$ of phenol completely within a short time span of $24 \mathrm{~h}$. Further, at this optimized medium constituents almost completely degradation of phenol has been achieved at $1500 \mathrm{mgl}^{-1}$ of phenol within a shorter time period of $94 \mathrm{~h}$. Further, at $1500 \mathrm{mgl}^{-1}$ of initial phenol more than $95.5 \%$ COD as well as $97.5 \%$ toxicity removal have been achieved by the $P$. citronellolis NS1.

\section{CONCLUSIONS}

The culture medium components have been optimized using CCD and the optimum values of the culture conditions are as follows: $0.094 \mathrm{mgl}^{-1}$ of $\mathrm{NaCl}, 0.019 \mathrm{mgl}^{-1} \mathrm{FeCl} 3$ and $0.1681 \mathrm{mgl}^{-1}$ of $\mathrm{MgSO}_{4}$. At this optimized medium components almost completely degradation of $1500 \mathrm{mgl}^{-1}$ of phenol has been attained within a shorter time period of 94 h. The application of nonconventional, statistically based design techniques proved valuable for increasing the efficiency of phenol biodegradation by the newly isolated Pseudomonas citronellolis N1. Thus, indigenous pseudomonas species can be a possible option for the treatment of coke oven wastewater.

\section{ACKNOWLEDGEMENTS}

The authors acknowledge the financial support received from the Science and Engineering Research Board (File No. YSS/201S/000984), Government of India, New Delhi for carrying out this research work.

\section{REFERENCES}

1. D. Naidu, N. Panigrahi, J. Mishra and N.K Sahoo, "Assessing the potential of mesoporous MCM-41 nanoparticles for treatment of phenolic wastewater," Int J. Nano. Biomater., vol.7, no 2, pp. 124-139, 2018.

2. S. Tsai and R. Juang, "Biodegradation of phenol and sodium salicylate mixtures by suspended Pseudomonas putida CCRC 14365," J. Hazard. Mater., vol. 138, no. 3 , pp. 125-132, 2006.

3. J. Bai, J. Wen, H. Li, and Y. Jiang, "Kinetic modeling of growth and biodegradation of phenol and $\mathrm{m}$-cresol using

Blue Eyes Intelligence Engineering

\& Sciences Publication

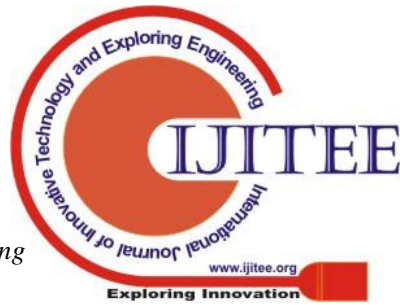


Alcaligenes faecalis," Process Biochem., vol. 42, pp. 510-517, 2007.

4. P. Pal and R. Kumar, "Treatment of coke wastewater: A critical review for developing sustainable management strategies," Sep. Purif. Rev., vol. 43, no. 2, pp. 89-123, 2014.

5. M. Trapido and J. Kallas, "Advanced Oxidation Processes for the Degradation and Detoxification of 4 Nitrophenol," Environ. Technol., vol. 21, no. October 2014, pp. 37-41, 2000.

6. P. Saravanan, K. Pakshirajan, and P. Saha, "Growth kinetics of an indigenous mixed microbial consortium during phenol degradation in a batch reactor," Bioresour. Technol., vol. 99, no. 1, pp. 205-209, 2008.

7. Y.M. Kim, D. Park, D.S. Lee and J.M. Park, “'Inhibitory effects of toxic compounds on nitrification process for cokes wastewater treatment', Journal of Hazardous Materials, vol. 152, No. 3, pp.915-921, 2008

8. Y. M. Chao, I. C. Tseng, and J. S. Chang, "Mechanism for sludge acidification in aerobic treatment of coking wastewater," J. Hazard. Mater., vol. 137, no. 3, pp. 1781-1787, 2006.

9. N.K. Sahoo, K. Pakshirajan, P.K. Ghosh, "Enhancing the biodegradation of 4-chlorophenol by Arthrobacter chlorophenolicus A6 via medium development," Int. Biodeterior. Biodegrad. Vol 64, pp 474-480, 2010.

10. K. Nordin, M. Unell, and J. K. Jansson, "Novel 4Chlorophenol Degradation Gene Cluster and Degradation Route via Hydroxyquinol in Arthrobacter chlorophenolicus A6," Appl. Environ. Microbiol., vol. 71, no. 11, pp. 6538-6544, 2005.

11. Y. R. Abdel-fattah, H. M. Saeed, Y. M. Gohar, and M. A. El-baz, "Improved production of Pseudomonas aeruginosa uricase by optimization of process parameters through statistical experimental designs," Process Biochem., vol. 40, pp. 1707-1714, 2005.

12. P. Mundra, K. Desai, and S. S. Lele, "Application of response surface methodology to cell immobilization for the production of palatinose," Bioresour. Technol., vol. 98, pp. 2892-2896, 2007.

13. M. Elibol, "Optimization of medium composition for actinorhodin production by Streptomyces coelicolor A3 ( 2 ) with response surface methodology," Process Biochem., vol. 39, pp. 1057-1062, 2004.

14. APHA, Standard methods for the examination of water and wastewater, $21^{\text {th }}$ ed., Washington, DC., 2005.

15. P. Pattanaik, N. Panigrahi, J. Mishra, N. K. Sahoo, B. P. Dash, and D. Rath, "Evaluation of MCM-41 nanoparticles for removal of phenol contents from cokeoven wastewater," J. Hazardous, Toxic, Radioact. Waste, vol. 22, no. 2, pp. 1-9, 2018.

16. M. S. Tanyildizi, O. Dursun, and M. Elibol, "Optimization of a -amylase production by Bacillus sp . using response surface methodology," Process Biochem., vol. 40, pp. 2291-2296, 2005.

17. N. K. Sahoo, K. Pakshirajan, P. K. Ghosh, and A. Ghosh, "Biodegradation of 4-chlorophenol by Arthrobacter chlorophenolicus A6: effect of culture conditions and degradation kinetics," Biodegradation, vol. 22, pp. 275286, 2011.

18. G.- Yull Rhee, B. Bush, C. M. Bethoney, A. DeNucci, H. -m. Oh, and R. C. Sokol, "Anaerobic Dechlorination of aroclor 1242 as affected by some Environmental Conditions," Environ. Toxicol. Chemisrry, vol. 12, pp. 1033-1039, 1993.

19. A. C. Heimann, A. K. Friis, and R. Jakobsen, "Effects of sulfate on anaerobic chloroethene degradation by an enriched culture under transient and steady-state hydrogen supply," Water Res., vol. 39, pp. 3579-3586, 2005.

20. B. Kuipers and W. R. Cullen, "Reductive Dechlorination of Nonachlorobiphenyls and Selected Octachlorobiphenyls by Microbial Enrichment Cultures," Environ. Sci. Technol., vol. 33, no. 604, pp. 3579-3585, 1999.

21. G. J. Stanlake and R. K. Finn, "Isolation and Characterization of a Pentachlorophenol- Degrading Bacterium," Appl. Environ. Microbiol., vol. 44, no. 6, pp. 1421-1427, 1982.

\section{AUTHORS PROFILE}

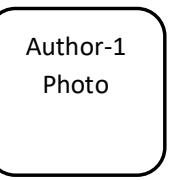

First Author Namita Panigrahi, completed her Msc life science from National Institute of Technology, Rourkela, India. Currently, he is doing $\mathrm{PhD}$ in the Department of Chemistry Environmental Science and Technology Programme, Institute of Technical Education and Research, Siksha 'O'Anusandhan, Deemed to be University, India, Her area of research is biodegradation treatment of phenolic wastewater.

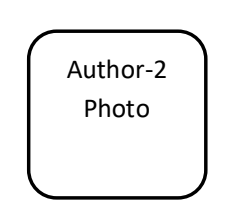

Second Author Manas Barik, completed her Msc Environmental Science from Sambalpur University, Jyoti Vihar, Burla, India. Currently, he is doing $\mathrm{PhD}$ in the Department of Chemistry Environmental Science and Technology Programme, Institute of Technical Education and Research, Siksha'O'Anusandhan, Deemed to be University, India, His area of research is treatment of coke oven wastewater using multistage bioreactor system.
Author-3 Photo
Third Author N.K. Sahoo is working as an Associate Professor in the Department of Department of Chemistry Environmental Science and Technology Programme, Institute of Technical Education and Research, Siksha'O'Anusandhan, Deemed to be University, India, After M-Tech in Biotechnology from Jadavapur University, Kolkata India, he has received his $\mathrm{PhD}$ from Centre for the Environment from Indian Institute of Technology Guwahati, India. His research interests are in the area of industrial wastewater treatment using photo catalytic nano-composites, nano-adsorbent and bioremediation techniques. He has published over 20 papers in peer reviewed international journals book and book chapter. He is a invited reviewer of many scientific journals including, CLEAN - Soil, Air, Water, Wiley publisher International Journal of Hydrogen Energy, Elsevier Publisher, Industrial and Engineering and Chemistry Research, ACS, Publisher, Biodegradation, Springer publisher, Chemical Technology and Biotechnology, Wiley publisher, Review in Environmental Science and Biotechnology, Springer publisher, Environmental Process Springer publisher. He is life member of biotechnology society of India. 